\title{
Chronic Subdural Hematoma Preceded by High-Impact Trauma: Does the Intensity of Trauma Influence the Pathogenesis of Traumatic Chronic Subdural Hematoma?
}

\author{
Ki-Su PARK ${ }^{1, *}$, Chang-Heon LEE ${ }^{2, *}$, Seong-Hyun PARK ${ }^{1}$, Sung-Kyoo HWANG ${ }^{1}$, Jeong-Hyun HWANG ${ }^{1}$ \\ ${ }^{1}$ Kyungpook National University School of Medicine, Department of Neurosurgery, Daegu, Republic of Korea \\ ${ }^{2}$ Hana General Hospital, Department of Neurosurgery, Cheongju, Republic of Korea \\ *These authors contributed equally to this paper.
}

\section{ABSTRACT}

AIM: The purpose of this study was to investigate whether the intensity of trauma influences the pathogenesis of traumatic chronic subdural hematoma (CSDH).

MATERIAL and METHODS: Thirty-one patients treated surgically for traumatic CSDH were divided into high-impact and lowimpact groups according to the intensity of trauma. They were respectively evaluated with respect to clinical and radiological findings at presentation, and the subdural concentrations of interleukin-6 (IL-6), interleukin-8 (IL-8), vascular endothelial growth factor (VEGF), basic fibroblast growth factor, and beta-trace protein (BTP) [a highly specific protein in the cerebrospinal fluid (CSF)] related to the pathogenesis of CSDH. If $\beta$ TP (subdural fluid/serum) was $>2$, an admixture of CSF to the subdural fluid was indicated. RESULTS: The $\beta$ TP (subdural fluid/serum) was $>2$ in all patients with a traumatic CSDH. The mean concentration of subdural $\beta$ TP in the high-impact group was higher than in the low-impact group $(6.1 \mathrm{mg} / \mathrm{L}$ versus $3.9 \mathrm{mg} / \mathrm{L})$, and the difference was statistically significant $(\mathrm{p}=0.02)$. In addition, mean concentrations of IL-6, IL-8 and VEGF were higher in the high-impact group, as compared to the low-impact group, though the differences did not reach statistical significance.

CONCLUSION: Trauma may be related to CSF leakage into the subdural space in CSDH, and the intensity of trauma may influence the amount of CSF leakage. Although there is no direct correlation between the amount of CSF leakage and other subdural molecules, the intensity of trauma may be associated with larger concentrations of molecules in traumatic CSDH.

KEYWORDS: Trauma, Chronic subdural hematoma, Beta-trace protein, Cerebrospinal fluid

\section{INTRODUCTION}

$(2$ hronic subdural hematoma $(\mathrm{CSDH})$ is a commonly encountered neurosurgical disease that is more likely to age, alcoholism, abnormal coagulation, dementia, seizure disorder, or after cerebrospinal fluid (CSF) diversion $(13,17,18)$. Although the pathophysiology of $\mathrm{CSDH}$ has been controversial over the last several years, the ultrastructural anatomy of the meninges and the neo-membrane of hematoma have been recently clarified. Additionally, the roles of inflammatory, fibrinolytic, angiogenic, and coagulation-system factors in the CSDH have been investigated $(3,7,8,12,22,32)$. Currently, $\mathrm{CSDH}$ is considered a chronic self-perpetuating inflammatory process involving the dura mater.

Trauma is probably the most important risk factor for $\mathrm{CSDH}$. Rupture of transversing veins by trauma is commonly known 
as the initial mechanism in the development of CSDH (14), and the posttraumatic subdural hygroma due to a traumatic tear of arachnoid membrane can cause a CSDH (23). In patients with traumatic CSDH, the majority of trauma histories consist of minor traumas (11), but traumas vary from highimpact traumas such as falls, slips, motor vehicle collisions, and assaults to low-impact traumas such as slight collisions. However, it is unknown whether the intensity of trauma influences the pathogenesis of traumatic CSDH.

The purposes of this study were the following: 1) to measure subdural molecules related with the pathogenesis of CSDH, such as typical inflammatory cytokines [interleukin-6 (IL-6) and interleukin-8 (IL-8)], angiogenic growth factors [vascular endothelial growth factor (VEGF) and basic fibroblast growth factor (bFGF)], and a highly specific protein in CSF [betatrace protein ( $(\mathrm{TP})$ ]; and 2) to analyze the possible connection between the intensity of trauma and the pathogenesis of traumatic CSDH.

\section{MATERIAL and METHODS}

\section{Patient Population}

Between January and December 2013, 49 consecutive patients with trauma histories had been admitted to our institute for surgical management of CSDH. Of these, 18 patients with the following risk factors were excluded from this study, as these patients had greater chance of adversely affecting the results: concomitant hematologic disease $(n=1)$; long-term use of thrombolytics, anti-coagulants, or anti-inflammatory therapy or hemodialysis $(n=12)$; dementia $(n=2)$; or presence of a ventriculoperitoneal shunt for hydrocephalus $(n=3)$. The remaining 31 patients were enrolled in this prospective study.

The traumatic CSDHs were divided into high-impact and lowimpact groups according to the intensity of trauma. A highimpact head trauma was defined as a head injury by a strong force in a short moment, such as a fall, slip, motor vehicle collision, or assault. They occur suddenly and sometimes are accompanied by altered consciousness. Based on the distribution of pain visual analogue scale (VAS), patients should describe their pain intensity as moderate or severe (45$100 \mathrm{~mm}$ ) at the time of trauma. A low-impact head trauma was defined as a head injury from a slight collision, and patients sometimes do not remember the exact date of trauma. Based on the distribution of pain VAS, patients usually describe their pain intensity as none or mild $(0-44 \mathrm{~mm})$ at the time of trauma.

According to the density of preoperative CT scanning, CSDHs were radiologically classified into 2 groups, homogenous and heterogenous groups (22). All patients underwent burr hole drainage. Age, gender, medical history, presence of a trauma history, pain VAS, neurological condition on admission [assessed by the Markwalder grading scale (16)], maximal thickness of CSDH, the laterality of $\mathrm{CSDH}$, and the recurrence were evaluated.
Measurement of Interleukin-6 (IL-6), Interleukin (IL-8), Vascular Endothelial Growth Factor (VEGF) and Basic Fibroblast Growth Factor (bFGF)

Samples of the subdural hematoma and venous blood were obtained at burr hole drainage. The subdural hematoma sample was obtained through the dura mater with a disposable plastic syringe via a burr hole. Peripheral venous blood samples were also taken from the patients. All samples were collected into siliconized vaccum tubes containing protamine sulfate and ethylene diamine tetraacetic acid and were immediately centrifuged at 2500 to $3000 \mathrm{rpm}$ for 10 minutes. The supernatants were stored in sealed polypropylene tubes at $-70^{\circ} \mathrm{C}$ until analysis. Concentrations of IL-6, IL-8, VEGF, and bFGF in the subdural fluid and venous blood were measured with an ELISA kit (R\&D System Co, Minneapolis, Minn, dilution 1:100) using monoclonal antibodies.

\section{Measurement of Beta-Trace Protein ( $\beta$ TP)}

The $\beta$ TP is a marker highly specific for CSF, and more than $99 \%$ of the $\beta$ TP is produced by the choroid plexus in the central nervous system, and is obtained in the CSF. The $\beta$ TP concentration in CSF is 32 to 35 times higher than the $\beta T P$ concentration in the serum $\left(\beta\right.$ TP $\left._{\text {SER }}\right)(1,24)$. Samples of subdural fluid with a $\beta$ TP concentration $\left(\beta T P_{S F}\right)$ at least twice as high as the $\beta \mathrm{TP}_{\text {SER }}\left(\beta \mathrm{TP}_{(\mathrm{SF} / \mathrm{SER})}>2\right.$, corresponding to a rate of at least $5 \% \mathrm{CSF}$ in the subdural fluid) were considered indicative of the presence of CSF in the subdural fluid. If the ratio of $\beta \mathrm{TP}_{(\mathrm{SF} / \mathrm{SER})}$ in the subdural fluid was $<2$, a CSF admixture to the subdural fluid was not considered to be present (9). In addition, the concentration of $\beta$ TP reflected the amount of CSF present in the CSDH (12).

Levels of $\beta T P$ in the subdural fluid and serum were measured with an ELISA kit [Cayman Chemical, Ann Arbor, MI, USA, dilution 1:100 (subdural fluid), 1:10 (serum)] using monoclonal antibodies.

\section{Statistical Analysis}

The levels of IL-6, IL-8, VEGF, bFGF and $\beta$ TP in the CSDHs were compared according to the intensity of trauma, respectively. Statistical analysis was performed using the chi-square test and the Mann-Whitney test. Data are presented as the mean \pm standard deviation. All analyses were performed using SPSS 14.0 for Windows. A p-value $<0.05$ was accepted as the threshold for statistical significance.

\section{RESULTS}

\section{Clinical and Radiological Data}

Thirty one patients were enrolled in the study and their main characteristics are summarized in Tables I and II. There were 25 men and 6 women, with ages ranging from 38 to 97 (average 68.9 years). Seventeen patients $(55 \%)$ reported high-impact head traumas, and 14 patients (45\%) reported low-impact head trauma. High-impact traumas consisted of slips (10), traffic accidents (4), a fall (2), and being hit with a bottle (1). Fourteen patients with a low-impact head trauma remembered slight collisions. The Markwalder grading scale 
Table I: Demographic Data of 31 Patients with Traumatic Chronic Subdural Hematoma

\begin{tabular}{|c|c|c|c|c|c|c|c|c|c|}
\hline Trauma & & $\begin{array}{c}\text { Age (yrs), } \\
\text { Sex }\end{array}$ & $\begin{array}{c}\text { Pain VAS } \\
\text { (mm) }\end{array}$ & MGS & $\begin{array}{c}\text { Days from } \\
\text { Trauma }\end{array}$ & CT density & $\begin{array}{c}\text { CSDH } \\
\text { thickness } \\
\text { (mm) }\end{array}$ & Bilateral & Recurrence \\
\hline \multirow{17}{*}{$\begin{array}{l}\text { High } \\
\text { impact } \\
(n=17)\end{array}$} & \multirow{10}{*}{ Slip } & $73, \mathrm{M}$ & 78 & 1 & 23 & Heterogenous & 13 & + & + \\
\hline & & $74, \mathrm{M}$ & 84 & 2 & 26 & Homogenous & 18 & - & - \\
\hline & & $59, \mathrm{M}$ & 90 & 2 & 40 & Heterogenous & 20 & - & - \\
\hline & & $65, M$ & 63 & 3 & 14 & Heterogenous & 21 & - & - \\
\hline & & $80, \mathrm{M}$ & 52 & 2 & 10 & Heterogenous & 18 & + & - \\
\hline & & $74, \mathrm{~F}$ & 74 & 2 & 30 & Heterogenous & 21 & - & - \\
\hline & & $51, \mathrm{M}$ & 82 & 2 & 20 & Heterogenous & 16 & - & - \\
\hline & & $80, \mathrm{~F}$ & 80 & 2 & 48 & Homogenous & 8 & - & - \\
\hline & & $57, \mathrm{M}$ & 57 & 1 & 63 & Homogenous & 9 & + & - \\
\hline & & $97, \mathrm{M}$ & 76 & 3 & 32 & Heterogenous & 18 & - & - \\
\hline & \multirow{4}{*}{$\begin{array}{l}\text { Traffic } \\
\text { accident }\end{array}$} & $58, \mathrm{M}$ & 85 & 2 & 60 & Heterogenous & 29 & - & - \\
\hline & & $38, \mathrm{M}$ & 92 & 1 & 63 & Homogenous & 17 & - & - \\
\hline & & $77, \mathrm{M}$ & 67 & 1 & 109 & Heterogenous & 20 & - & - \\
\hline & & $64, \mathrm{M}$ & 66 & 2 & 17 & Heterogenous & 26 & - & - \\
\hline & \multirow{2}{*}{ Fall } & $57, \mathrm{M}$ & 84 & 1 & 34 & Homogenous & 10 & - & - \\
\hline & & $50, \mathrm{M}$ & 76 & 1 & 26 & Heterogenous & 20 & - & - \\
\hline & Assault & $86, \mathrm{M}$ & 83 & 1 & 30 & Heterogenous & 10 & - & - \\
\hline \multirow{14}{*}{$\begin{array}{l}\text { Low } \\
\text { impact } \\
(n=14)\end{array}$} & \multirow{14}{*}{$\begin{array}{l}\text { Slight } \\
\text { collision }\end{array}$} & $76, \mathrm{M}$ & 10 & 1 & 34 & Homogenous & 18 & + & - \\
\hline & & $71, \mathrm{M}$ & 31 & 2 & 23 & Homogenous & 20 & - & + \\
\hline & & $80, F$ & 24 & 3 & 25 & Heterogenous & 22 & - & - \\
\hline & & $66, M$ & 22 & 2 & 37 & Homogenous & 16 & - & - \\
\hline & & $62, \mathrm{~F}$ & 15 & 2 & 28 & Heterogenous & 14 & - & - \\
\hline & & $74, \mathrm{M}$ & 26 & 1 & 31 & Homogenous & 21 & - & - \\
\hline & & $74, \mathrm{M}$ & 30 & 1 & 41 & Heterogenous & 12 & - & - \\
\hline & & $71, \mathrm{M}$ & 18 & 1 & 29 & Heterogenous & 26 & + & - \\
\hline & & $80, F$ & 32 & 2 & 26 & Heterogenous & 26 & - & - \\
\hline & & $74, \mathrm{M}$ & 17 & 2 & 35 & Homogenous & 11 & - & - \\
\hline & & $82, \mathrm{~F}$ & 10 & 1 & 47 & Homogenous & 22 & - & - \\
\hline & & $73, \mathrm{M}$ & 24 & 2 & 30 & Homogenous & 15 & - & - \\
\hline & & $72, \mathrm{M}$ & 20 & 2 & 48 & Homogenous & 16 & - & - \\
\hline & & $40, \mathrm{M}$ & 13 & 1 & 27 & Homogenous & 13 & - & - \\
\hline
\end{tabular}

VAS: Visual analogue scale, MGS: Markwalder grading scale, CT: Computed tomography, CSDH: Chronic subdural hematoma, M: Male, F: Female. 
ranged from 1 to 3 with a mean of 1.7. The mean time interval between head trauma and surgery for $\mathrm{CSDH}$ was 35.7 days (range, 10 to 109 days). Two patients had a recurrence (6.5\%) that required a second operation. There was statistically a significant difference in terms of pain VAS between highimpact and low-impact groups (high-impact group: mean 75.8, range 52-92; low-impact group: mean 20.9, range 10-32; $\mathrm{p}<0.001$ ), but there were no statistically significant differences in terms of other demographic characteristics, recurrence and Markwalder grading scale between high-impact and lowimpact groups.

Computed tomography showed bilaterality of $\mathrm{CSDH}$ in 5 patients (16\%), and 3 out of 5 patients in that group had a high-impact trauma. The mean thickness of $\mathrm{CSDH}$ was 17.6 $\mathrm{mm}$ (range, 8 to $29 \mathrm{~mm}$ ). There were no statistically significant differences in terms of bilaterality and thickness of CSDH between the two groups. However, the correlation between the intensity of trauma and the CT density missed statistical significance by a small margin $(p=0.052)$, and patients with a high-impact trauma showed more heterogenous CT densities.

\section{Laboratory Findings}

All concentrations of IL-6, IL-8, VEGF, bFGF and $\beta$ TP from the CSDHs were higher than the values in the peripheral venous blood. The ratio of $\beta \mathrm{TP}_{\text {(SF/SER) }}$ was $>2$ in $100 \%$ of the patients with a CSDH. We compared concentrations of IL-6, IL-8, VEGF, bFGF and $\beta$ TP from the CSDHs according to the intensity of trauma, respectively (Table III).

Table II: Comparison of Demographic Data and CT Findings Between High-Impact Group and Low-Impact Trauma Group

\begin{tabular}{|c|c|c|c|}
\hline Parameter & $\begin{array}{l}\text { High-impact trauma group } \\
\qquad(n=17)\end{array}$ & $\begin{array}{l}\text { Low-impact trauma group } \\
\qquad(n=14)\end{array}$ & $p$ value \\
\hline Mean age in yrs (range) & $67.1(38-97)$ & $71.1(40-82)$ & 0.38 \\
\hline Male: Female & $15: 2$ & $10: 4$ & 0.37 \\
\hline Pain visual analogue scale & $75.8(52-92)$ & $20.9(10-32)$ & $<0.001^{*}$ \\
\hline Mean days from Trauma (range) & $37.9(10-109)$ & $32.9(23-48)$ & 0.89 \\
\hline Recurrence (\%) & $1(6 \%)$ & $1(7 \%)$ & 1 \\
\hline \multicolumn{4}{|l|}{ CT findings } \\
\hline Mean thickness in mm (range) & $17.3(8-29)$ & $18.0(11-26)$ & 0.71 \\
\hline Heterogenous (\%) & $12(70.6 \%)$ & $5(35.7 \%)$ & 0.052 \\
\hline
\end{tabular}

${ }^{*} P$ value $<0.05$ indicates a significant difference.

Table III: Comparison of Subdural Fluid Concentrations of Molecular Markers Between High-Impact and Low-Impact Trauma Groups of Patients with Traumatic CSDH

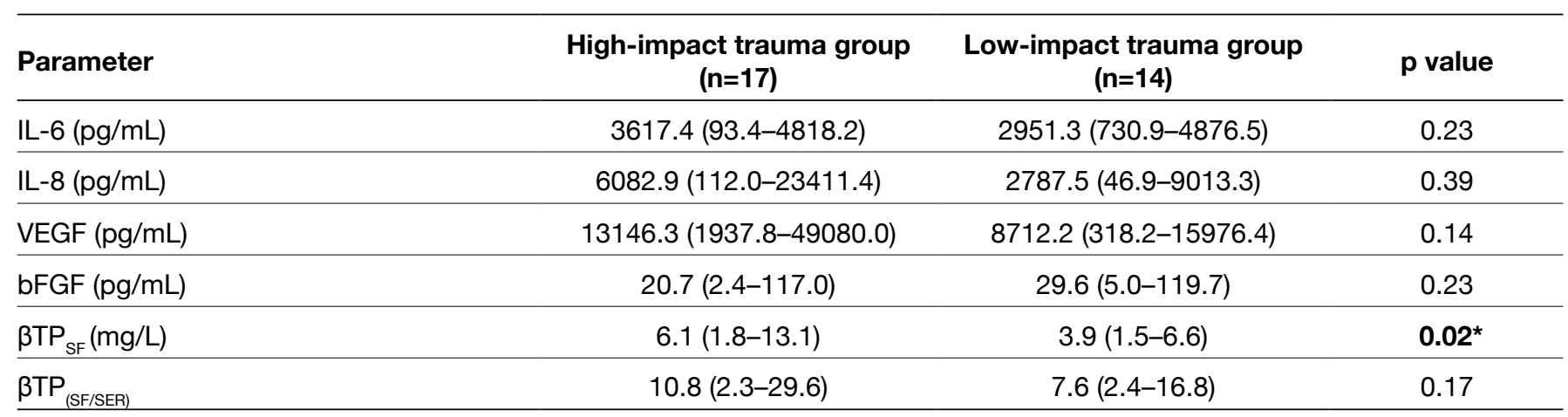

$\boldsymbol{\beta T P}_{S F}:$ Beta-trace protein in subdural fluid, $\boldsymbol{\beta T P}_{\text {SER }}$ : Beta-trace protein in serum, IL-6: Interleukin-6, IL-8: Interleukin-8, VEGF: Vascular endothelial growth factor, bFGF: Basic fibroblast growth factor.

${ }^{*} P$ value $<0.05$ indicates a significant difference. 
The mean concentrations of IL-6, IL-8, and VEGF (but not bFGF) from the CSDH in the high-impact group were higher than those from CSDH in the low-impact group (IL-6 = 3617.4 $\mathrm{pg} / \mathrm{mL}, \mathrm{IL}-8=6082.9 \mathrm{pg} / \mathrm{mL}$, VEGF $=13146.3 \mathrm{pg} / \mathrm{mL}$ versus IL-6 $=2951.3 \mathrm{pg} / \mathrm{mL}, \mathrm{IL}-8=2787.5 \mathrm{pg} / \mathrm{mL}$, VEGF $=8712.2 \mathrm{pg} /$ $\mathrm{mL}$ ), but there were no statistically significant differences, respectively.

The mean concentration of $\beta \mathrm{TP}_{\mathrm{SF}}$ from the CSDH in the highimpact group was higher than it was in the low-impact group, and the difference was statistically significant (high-impact group: mean $6.1 \mathrm{mg} / \mathrm{L}$, range $1.8-13.1 \mathrm{mg} / \mathrm{L}$; low-impact group: mean $3.9 \mathrm{mg} / \mathrm{L}$, range $1.5-6.6 \mathrm{mg} / \mathrm{L} ; \mathrm{p}=0.02)$. The ratio of $\beta$ TP $_{(\text {SF/SER })}$ from the CSDH in the high-impact group was higher than it was in low-impact group, but the difference was not statistically significant (high-impact group: mean 10.8, range 2.3-29.6; low-impact group: mean 7.6, range 2.4-16.8; $\mathrm{p}=0.17)$.

\section{DISCUSSION}

Pathogeneses of $\mathrm{CSDH}$ remain unclear. However, trauma is known to be the most important risk factor for the development of $\mathrm{CSDH}$. Head traumas probably result in small oligo- or asymptomatic subdural hemorrhages due to the tearing of a bridging vein, and subdural hemorrhages may induce neomembrane formation (29).

The inflammatory and angiogenic process of the neomembrane, along with the cycle of re-bleeding, coagulation, and fibrinolysis are hypothesized to be at the center of the development and progression of CSDHs $(4,6,8,12,19,30,31)$. In addition, traumatic subdural hygroma, defined as an accumulation of cerebrospinal fluid in the subdural space after trauma, is frequently associated with the development of CSDH (23). As a result, many coagulofibrinolytic factors, inflammatory cytokines, angiogenic growth factors, and highly specific proteins for CSF have been associated with CSDHs $(3,7,8,12,22,32)$. We hypothesized that higher intensity head traumas prior to the CSDH may be associated with greater levels of these molecular markers, especially suggesting more CSF admixture into the subdural space.

Some studies have suggested that CSF leakage into the subdural space may influence the development of $\mathrm{CSDH}$. Kristof et al. (12) reported that $\beta$ TP, a highly specific CSF marker, was shown to be present in the subdural fluid of the vast majority of CSDH patients (94\%) in his study, and suggested that CSF leakage into the subdural space could be involved in the pathogenesis of CSDH. Ohno et al. (21) reported that an increase in postoperative subdural fluid collection over the course of 1 week was a significant risk factor for CSDH after aneurysm clipping. And, Tanaka and Ohno (29) reported that nearly $50 \%$ of patients with asymptomatic subdural fluid collection after head trauma developed CSDH. In our study, the ratio of $\beta \mathrm{TP}_{\text {(SF/SER) }}$ was $>2$ in $100 \%$ of our patients, and CSF was considered to be present in each case of $\mathrm{CSDH}$.

CSF leakage into the subdural space after head trauma may correlate with neo-membrane formation. Tanaka and Ohno (29) suggested that the causes of neo-membrane formation can be attributed to both the presence of a subdural collection of CSF contaminated with a small number of blood cells and blood-derived factors and the dural inflammatory reaction. And, Komatsu et al. (10) demonstrated that CSF with a small number of blood cells, including inflammatory cytokines, persists for a certain period in the subdural space, and such fluid collection causes inflammatory changes in the dura mater and neo-membrane formation on the inner side of the dura mater. Although the mechanism of CSF leakage (and its component $\beta T P$ ) in to the subdural space in CSDH remains unknown, two hypotheses were suggested: (1) CSF (and its component $\beta$ TP) enters the subdural space of CSDH through the arachnoid tear that acts as a valve and (2) CSF (and its component $\beta$ TP) crosses the inner membrane of the CSDH into the subdural space by diffusion/exudation (12). The former mechanism is supported by the high prevalence of preceding head trauma in patients with $\mathrm{CSDH}$ and subdural hygroma $(\mathrm{SH})$, by the sporadic intraoperative identification of arachnoid tears, and by sporadic accumulation of tracer within the subdural space during cisternography in patients with $\mathrm{SH}$, but the latter mechanism has not yet been observed or assessed $(2,4,5,15,26,27)$. In our study, we hypothesized that higher intensity head traumas may be indicative of more CSF leakage into the subdural space. A result of our study was that the mean concentration of $\beta \mathrm{TP}_{\mathrm{SF}}$ in the high-impact group was higher than it was in the low-impact group $(p=0.02)$. Since greater levels of $\beta T P_{S F}$ are associated with higher levels of CSF admixture, the high intensity of a head trauma may be a clinical indicator of greater CSF leakage into the subdural space.

Many inflammatory cytokines and angiogenic growth factors have been associated with the neo-membrane formation of CSDHs. Suzuki et al. (28) reported that the level of IL-6 and IL-8 in the subdural fluid of patients with CSDH were much higher than those in the peripheral blood and subdural effusion, and suggested that the immature outer membrane may be the source of the cytokines. Shono et al. (25) reported that enhanced production of VEGF by macrophages and vascular endothelial cells in the outer membrane is thought to be pathogenetically important in $\mathrm{CSDH}$. In our study, the concentrations of IL-6, IL-8, VEGF, and bFGF in the CSDH of all patients were higher than in the peripheral blood. The concentrations of IL-6, IL-8, and VEGF (but not bFGF) in the high-impact group were higher than those in the low-impact group. Although there were no significant differences between two groups, potentially due to the small sample size, the greater levels of molecules in the high-impact group may be indicative of greater inflammatory and angiogenic activities of the neo-membrane.

The appearance of CSDH on CT scans may be correlated with the levels of molecules related with pathogenesis of $\mathrm{CSDH}$. Frati et al. (3) reported that the concentrations of IL-6 and IL-8 were increased in the heterogenous types of CSDHs on CT scans. Nomura et al. (20) and Park et al. (22) described higher fibrinogen and higher D-dimer levels in the heterogenous types. They suggested that these findings appear to be associated with re-bleeding and evolution in CSDHs. In addition, Kristof et al. (12) reported that the amount of CSF leakage into 
the subdural space could influence the pathogenesis and recurrence of $\mathrm{CSDH}$ and subdural hygroma. In our study, statistical significance was missed by a small margin $(p=0.052)$ between intensity of trauma and CT densities, but CSDHs in the high-impact group showed more heterogeneous densities on the CT scans. In addition, they showed greater levels of molecules than those in the low-impact group. Furthermore, CSDHs in the high-impact group revealed greater CSF leakage into the subdural space. Although there was no statistically direct correlation between the amount of CSF leakage and levels of molecules, potentially due to the small sample size, the amount of CSF leakage may provide another possibility for the evolution and re-bleeding of traumatic $\mathrm{CSDH}$.

In the present study, we did not conduct a comparative study between patients with and without a recurrence, because the recurrent cases (6.5\%) were fairly low in number. In the future, a prospective study is needed to evaluate the relationship between the intensity of head trauma and the recurrence rate.

\section{CONCLUSION}

Trauma may be related to CSF leakage into the subdural space in traumatic CSDH, and greater impact intensity could be associated with more CSF leakage. Although there is no direct correlation between the amount of CSF leakage and other subdural molecules, we suggest that the amount of CSF leakage according to the intensity of trauma may influence neo-membrane formation and the concentrations of molecular markers, such as inflammatory cytokines and angiogenic growth factors. In addition, the intensity of trauma may provide another possibility for the evolution and re-bleeding of traumatic CSDH.

\section{ACKNOWLEDGMENT}

We thank Wade Martin of Medical Research International for his critical review of this manuscript.

\section{- REFERENCES}

1. Bachmann G, Petereit H, Djenabi U, Michel O: Predictive values of beta-trace protein (prostaglandin $D$ synthase) by use of laser-nephelometry assay for the identification of cerebrospinal fluid. Neurosurgery 50: 571-576; discussion 576-577, 2002

2. Baechli H, Nordmann A, Bucher HC, Gratzl O: Demographics and prevalent risk factors of chronic subdural haematoma: Results of a large single-center cohort study. Neurosurg Rev 27:263-266, 2004

3. Frati A, Salvati M, Mainiero F, Ippoliti F, Rocchi G, Raco A, Caroli E, Cantore G, Delfini R: Inflammation markers and risk factors for recurrence in 35 patients with a posttraumatic chronic subdural hematoma: A prospective study. J Neurosurg 100: 24-32, 2004

4. Fujisawa $H$, Nomura $S$, Tsuchida $E$, Ito $H$ : Serum protein exudation in chronic subdural haematomas: A mechanism for haematoma enlargement? Acta Neurochir 140:161-165; discussion 165-166, 1998
5. Gomori JM, Grossman RI: Mechanisms responsible for the MR appearance and evolution of intracranial hemorrhage. Radiographics 8:427-440, 1988

6. Hirashima Y, Endo S, Hayashi N, Karasawa K, Nojima S, Takaku A: Platelet-activating factor (PAF) and the formation of chronic subdural haematoma. Measurement of plasma PAF levels and anti-PAF immunoglobulin titers. Acta Neurochir 137:15-18, 1995

7. Hong HJ, Kim YJ, Yi HJ, Ko Y, Oh SJ, Kim JM: Role of angiogenic growth factors and inflammatory cytokine on recurrence of chronic subdural hematoma. Surg Neurol 71:161-165; discussion 165-166, 2009

8. Kitazono M, Yokota $\mathrm{H}$, Satoh $\mathrm{H}$, Onda $\mathrm{H}$, Matsumoto $\mathrm{G}$, Fuse A, Teramoto A: Measurement of inflammatory cytokines and thrombomodulin in chronic subdural hematoma. Neurol Med Chir 52: 810-815, 2012

9. Kleine TO, Damm T, Althaus H: Quantification of beta-trace protein and detection of transferrin isoforms in mixtures of cerebrospinal fluid and blood serum as models of rhinorrhea and otorrhea diagnosis. Fresenius J Anal Chem 366:382-386, 2000

10. Komatsu S, Takaku A, Hori S: Three cases of chronic subdural hematoma developing after direct aneurysmal surgery (author's transl). No Shinkei Geka 5:1273-1277, 1977

11. Krauss JK ML, Weigel R: Medical and surgical management of chronic subdural hematomas. In: Winn HR (ed). Neurological Surgery, $6^{\text {th }}$ ed. Saunders, 2011:535-543

12. Kristof RA, Grimm JM, Stoffel-Wagner B: Cerebrospinal fluid leakage into the subdural space: Possible influence on the pathogenesis and recurrence frequency of chronic subdural hematoma and subdural hygroma. J Neurosurg 108:275-280, 2008

13. Kwon TH, Park YK, Lim DJ, Cho TH, Chung YG, Chung HS, Suh JK: Chronic subdural hematoma: Evaluation of the clinical significance of postoperative drainage volume. J Neurosurg 93: 796-799, 2000

14. Lee KS: Natural history of chronic subdural haematoma. Brain Inj 18: 351-358, 2004

15. Markwalder TM: Chronic subdural hematomas: A review. J Neurosurg 54: 637-645, 1981

16. Markwalder TM, Reulen HJ: Influence of neomembranous organisation, cortical expansion and subdural pressure on the post-operative course of chronic subdural haematoma-an analysis of 201 cases. Acta Neurochir 79: 100-106, 1986

17. Murakami H, Hirose Y, Sagoh M, Shimizu K, Kojima M, Gotoh K, Mine Y, Hayashi T, Kawase T: Why do chronic subdural hematomas continue to grow slowly and not coagulate? Role of thrombomodulin in the mechanism. J Neurosurg 96:877884,2002

18. Nakaguchi H, Tanishima T, Yoshimasu N: Factors in the natural history of chronic subdural hematomas that influence their postoperative recurrence. J Neurosurg 95: 256-262, 2001

19. Nakaguchi H, Yoshimasu N, Tanishima T: Relationship between the natural history of chronic subdural hematoma and enhancement of the inner membrane on post-contrast CT scan. No Shinkei Geka 31:157-164, 2003 
20. Nomura S, Kashiwagi S, Fujisawa $H$, Ito $H$, Nakamura K: Characterization of local hyperfibrinolysis in chronic subdural hematomas by SDS-PAGE and immunoblot. J Neurosurg 81: 910-913, 1994

21. Ohno T, lihara K, Takahashi JC, Nakajima N, Satow T, Hishikawa T, Nagata I, Yamada K, Miyamoto S: Incidence and risk factors of chronic subdural hematoma after aneurysmal clipping. World Neurosurg 80: 534-537, 2013

22. Park SH, Kang DH, Park J, Hwang JH, Hwang SK, Sung JK,Hamm IS: Fibrinogen and D-dimer analysis of chronic subdural hematomas and computed tomography findings: A prospective study. Clin Neurol Neurosurg 113: 272-276, 2011

23. Park SH, Lee SH, Park J, Hwang JH, Hwang SK, Hamm IS: Chronic subdural hematoma preceded by traumatic subdural hygroma. J Clin Neurosci 15: 868-872, 2008

24. Schnabel C, Di Martino E, Gilsbach JM, Riediger D, Gressner AM, Kunz D: Comparison of beta2-transferrin and beta-trace protein for detection of cerebrospinal fluid in nasal and ear fluids. Clin Chem 50: 661-663, 2004

25. Shono T, Inamura T, Morioka T, Matsumoto K, Suzuki SO, Ikezaki K, Iwaki T, Fukui M: Vascular endothelial growth factor in chronic subdural haematomas. J Clin Neurosci 8: 411-415, 2001
26. So SK, Ogawa T, Gerberg E, Sakimura I, Wright W: Tracer accumulation in a subdural hygroma: Case report. J Nucl Med 17: 119-121, 1976

27. Stroobandt G, Fransen P, Thauvoy C, Menard E: Pathogenetic factors in chronic subdural haematoma and causes of recurrence after drainage. Acta Neurochir 137: 6-14, 1995

28. Suzuki M, Endo S, Inada K, Kudo A, Kitakami A, Kuroda K, Ogawa A: Inflammatory cytokines locally elevated in chronic subdural haematoma. Acta Neurochir 140: 51-55, 1998

29. Tanaka Y, Ohno K: Chronic subdural hematoma - an up-todate concept. J Med Dent Sci 60: 55-61, 2013

30. Vaquero J, Zurita M, Cincu R: Vascular endothelial growthpermeability factor in granulation tissue of chronic subdural haematomas. Acta Neurochir 144: 343-346; discussion 347, 2002

31. Weigel R, Hohenstein A, Schilling L: Vascular endothelial growth factor concentration in chronic subdural hematoma fluid is related to computed tomography appearance and exudation rate. J Neurotrauma 31: 670-673, 2014

32. Weigel R, Schilling L, Schmiedek P: Specific pattern of growth factor distribution in chronic subdural hematoma (CSH): Evidence for an angiogenic disease. Acta Neurochir 143:811818; discussion 819, 2001 